\title{
Comparison of antipsychotic medication effects on reducing violence in people with schizophrenia
}

Jeffrey W. Swanson, Marvin S. Swartz, Richard A. Van Dorn, Jan Volavka, John Monahan, T. Scott Stroup, Joseph P. McEvoy, H. Ryan Wagner, Eric B. Elbogen and Jeffrey A. Lieberman, on behalf of the CATIE investigators

\section{Background}

Violence is an uncommon but significant problem associated with schizophrenia.

\begin{abstract}
Aims
To compare antipsychotic medications in reducing violence among patients with schizophrenia over 6 months, identify prospective predictors of violence and examine the impact of medication adherence on reduced violence.
\end{abstract}

\section{Method}

Participants ( $n=1445)$ were randomly assigned to doubleblinded treatment with one of five antipsychotic medications. Analyses are presented for the intention-to-treat sample and for patients completing 6 months on assigned medication.

\section{Results}

Violence declined from $16 \%$ to $9 \%$ in the retained sample and from $19 \%$ to $14 \%$ in the intention-to-treat sample. No difference by medication group was found, except that perphenazine showed greater violence reduction than quetiapine in the retained sample. Medication adherence reduced violence, but not in patients with a history of childhood antisocial conduct. Prospective predictors of violence included childhood conduct problems, substance use, victimisation, economic deprivation and living situation. Negative psychotic symptoms predicted lower violence.

\section{Conclusions}

Newer antipsychotics did not reduce violence more than perphenazine. Effective antipsychotics are needed, but may not reduce violence unrelated to acute psychopathology.

\section{Declaration of interest}

J.W.S., M.S.S., R.A.V.D., T.S.S. and H.R.W. have received research support from Eli Lilly, M.S.S. has received consulting and educational fees from AstraZeneca, Bristol-Myers Squibb, Eli Lilly and Pfizer. T.S.S. has received consulting fees from Janssen, GlaxoSmithKline and Bristol-Myers Squibb. J.P.McE. has received research funding from AstraZeneca, Eli Lilly, Janssen and Pfizer, consulting or advisory board fees from Pfizer and Bristol-Myers Squibb, and lecture fees from Janssen and Bristol-Myers Squibb. J.A.L. has received research funding from AstraZeneca, Bristol-Myers Squibb, GlaxoSmithkline, Janssen and Pfizer, and consulting and education fees from AstraZeneca, Bristol-Myers Squibb, Eli Lilly, Forest, GlaxosmithKline, Janssen, Novartis, Pfizer and Solvay.
Violent behaviour, although infrequent among people with schizophrenia in the community, remains a costly and sometimes tragic problem associated with untreated psychosis, ${ }^{1}$ as well as with other causes. At present pharmacotherapy is the main type of intervention thought to mitigate psychosis, and by extension violence risk. ${ }^{2}$ However, information is still needed regarding the effectiveness of particular antipsychotic medications in reducing violence. Whether the second-generation antipsychotics are more effective at preventing community violence than firstgeneration antipsychotics has never been established. More broadly, the multiple predictors of violence in people with schizophrenia are not well understood, and it is unknown whether antipsychotic medication can reduce violent behaviour in general, or only when such behaviour is associated directly with psychosis.

Over the past decade a growing research literature has suggested that second-generation antipsychotics such as clozapine, olanzapine, risperidone, quetiapine and ziprasidone are effective in the treatment of patients with psychosis, including those expressing hostility, aggression and violent behaviour. ${ }^{2-8}$ Recently, however, the picture of success for these drugs has become somewhat clouded. Many observers are questioning whether secondgeneration antipsychotics offer an advantage, in light of mostly negative results from two large double-blind trials in the USA and the UK. ${ }^{9,10}$ Still, the evidence is mixed, as a recent large, naturalistic, follow-up study of consecutive first admissions for schizophrenia in Finland found that clozapine, olanzapine and (depot) perphenazine were more effective than haloperidol. ${ }^{11}$ Another large, naturalistic study of schizophrenia treatment in the USA found superior effectiveness for second-generation antipsychotics in reducing community violence over a 3-year followup period. ${ }^{2}$ These recent studies are informative as far as they go; to date, however, there has been no definitive randomised clinical trial of schizophrenia treatment examining community violence as an outcome. Further, no trial has examined whether antipsychotic medication adherence reduces community violence differentially in subgroups of patients with schizophrenia for whom violence is related to psychosis $v$. other causes of violence such as premorbid antisocial conduct history. The study reported here thus fills an important scientific gap.

We present findings from the National Institute of Mental Health (NIMH) Clinical Antipsychotic Trials of Intervention Effectiveness (CATIE) project, with violent behaviour as a treatment outcome. The aims of the study are threefold:

(a) to examine violence risk reduction after 6 months of treatment with one of four second-generation antipsychotics - olanzapine, risperidone, quetiapine or ziprasidone - compared with perphenazine, a representative first-generation antipsychotic

(b) to identify significant prospective clinical and non-clinical predictors of violent behaviour

(c) to examine whether the impact of medication adherence in reducing violence may depend on whether violent behaviour is associated with acute psychopathology or rooted in longstanding, developmental antisocial conduct problems. ${ }^{12}$ 
The trial was registered with www.clinicaltrials.gov (NCT00014001).

\section{Method}

\section{Study design}

The NIMH CATIE project is a national study investigating the effectiveness of antipsychotic medications. The study recruited 1493 patients with schizophrenia at 57 US sites. The research protocol was approved by local institutional review boards. Participants or their legal guardians gave written informed consent. The study was conducted between January 2001 and December 2004. In phase 1 of the trial participants were randomly assigned to treatment with perphenazine or one of four second-generation antipsychotics and then followed for up to 18 months in a doubleblind study. Patients who discontinued their assigned medication could enter phase 2 with a new random assignment to another second-generation antipsychotic. The findings presented here pertain to phase 1; more extensive information regarding the sample, including its broad inclusion criteria and its generalisability, appears elsewhere. ${ }^{13}$

The data for this analysis come from 1445 patients with available baseline violence data in a 6-month intention-to-treat analysis, and from a subset of 653 patients who completed 6 months of treatment with their initially assigned study medication (the retained sample; Fig. 1). When patients discontinued their assigned phase 1 study medication prior to 6 months, violence was assessed in an end-of-phase interview for the period from baseline to discontinuation; the last observation was carried forward for the intention-to-treat sample. For missing observations in that sample, baseline risk was carried forward. A total of 761 patients $(50 \%$ of the intention-to-treat sample) discontinued their initial study medication before 6 months had elapsed, owing to lack of efficacy $(n=231)$, problems with side-effects $(n=160)$, patient or advocate decision $(n=320)$ or another reason $(n=50)$. An additional 31 participants could not be included in the retained sample analysis because of missing data on violence at baseline or follow-up.

\section{Interventions}

Participants were given identical capsules containing olanzapine (7.5 mg), quetiapine $(200 \mathrm{mg})$, risperidone $(1.5 \mathrm{mg})$ or perphenazine $(8 \mathrm{mg})$. (Ziprasidone was approved for use by the Food and Drugs Administration after the study began, and was added in January 2002 as an identical capsule containing $40 \mathrm{mg}$.) Dosage was flexible, with medications given as one to four capsules daily, based on the study doctor's judgement. Overlap in the administration of the antipsychotic agents that patients received prior to study entry was permitted for the first 4 weeks after randomisation to allow for gradual transition to study medication. Concomitant medications were permitted throughout the trial, except for additional antipsychotic agents. Patients had monthly appointments with the study doctors. Patients with current tardive dyskinesia were not assigned to perphenazine.

\section{Measures}

The MacArthur Community Violence Interview was used to measure violent behaviour during the time between the baseline and the 6-month (or end-of-phase) interviews., ${ }^{2,14}$ The interview provides an assessment of violent behaviour at two levels of severity: minor violence, corresponding to battery without injury or weapon use; and serious violence, corresponding to any battery using a weapon or resulting in injury, any threat with a lethal weapon in hand, or any sexual assault. For this analysis we combined minor and serious violence because the base rate for serious violence was too low to support valid longitudinal and multivariable analyses, particularly for comparing treatment groups and examining violence in the key subgroups with and without childhood antisocial conduct history. ${ }^{12}$

We supplemented participant self-report information with family collateral interviews on parallel questions. A positive report

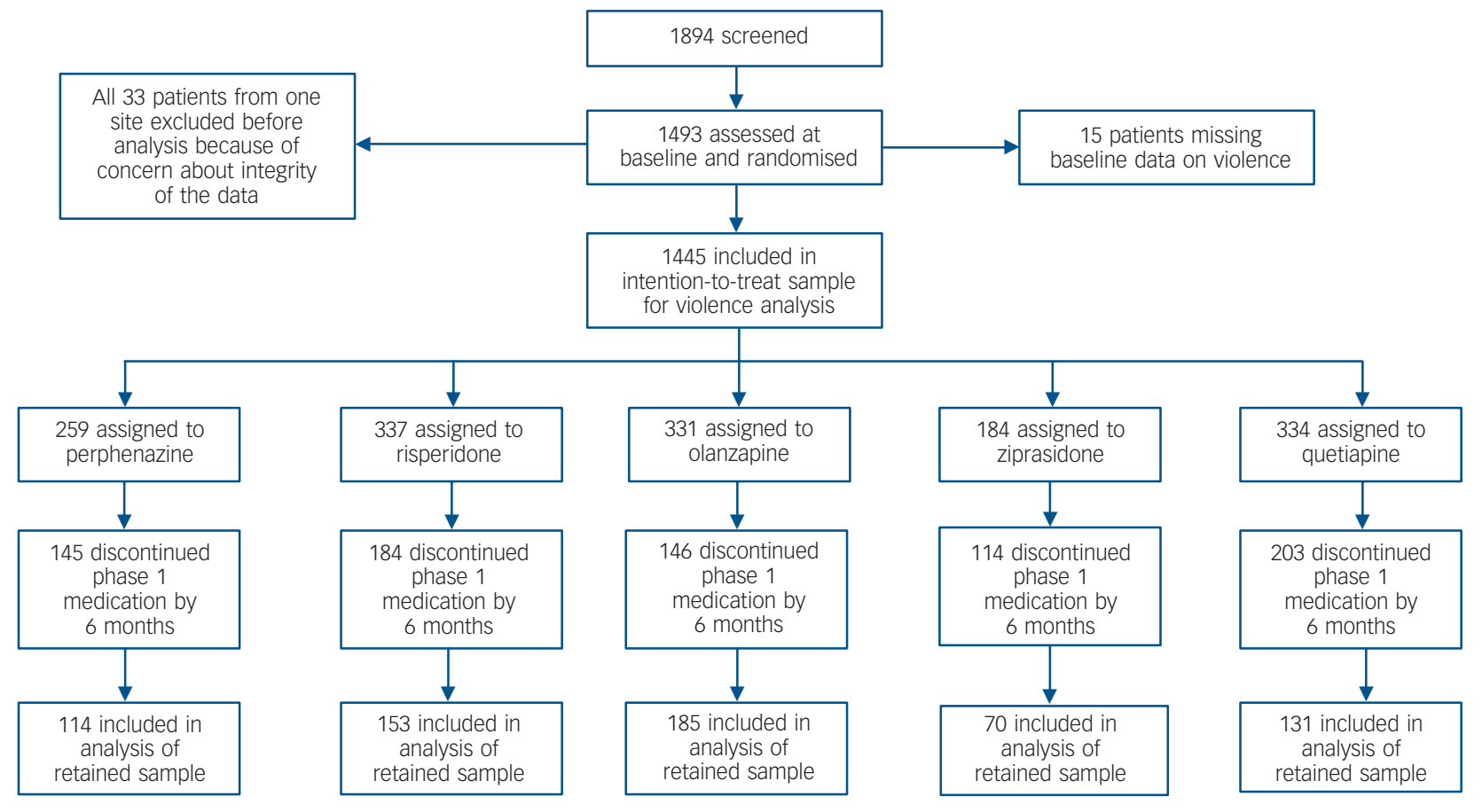

Fig. 1 Study enrolment and outcomes. 
from either the patient or family collateral informant was treated as a positive indicator of violence. Family collateral information regarding violent behaviour was available for 277 and 253 participants at baseline and 6 months respectively.

Potential baseline predictors were chosen for analysis based on prior clinical and epidemiological studies of risk factors related to violence and other outcomes for individuals with schizophrenia. ${ }^{2,14,16-19}$ Covariates were grouped into five domains: demographic characteristics, socio-economic and housing status; household composition and social contact; childhood risk factors; baseline clinical characteristics, impairment and functioning; and institutional contact prior to study enrolment. ${ }^{13}$ Analyses were controlled for design and site effects. Covariates were dichotomised if warranted by their distribution and/or non-linear association with violence. ${ }^{20}$

Social contact and support were measured with items modified from the Duke Social Support Scale. ${ }^{21}$ The Structured Clinical Interview for Axes I and II DSM-IV Disorders - Patient Edition (SCID-I/P) was used to assess childhood conduct problems. ${ }^{22}$ The Clinical Global Impression scale was used to rate the severity of participants' illness. ${ }^{23}$ The Positive and Negative Syndrome Scale (PANSS) was used to rate individual psychotic symptoms. ${ }^{24}$ Depressive symptoms were assessed with the Calgary Depression Scale for Schizophrenia. ${ }^{25}$ The Insight and Treatment Attitudes Questionnaire was used to measure awareness of mental health problems and acknowledgment of need for treatment. ${ }^{26}$ Substance misuse was assessed from multiple sources of information: hair and urine testing for drug use, self- and family-report, clinician ratings on the Alcohol Use and Drug Use scales, ${ }^{27}$ and SCID diagnostic assessment. ${ }^{22}$ The HeinrichsCarpenter Quality of Life Scale was used to measure functional performance. ${ }^{28}$ Adherence to study medication was measured by monthly pill counts. Other risk factors that were measured are described in more detail elsewhere. ${ }^{13}$ All assessments were conducted by trained clinical interviewers masked to random assignment.

\section{Analysis}

We first examined the unadjusted rates of violence from baseline to follow-up and compared these unadjusted rates in the randomised intention-to-treat and retained treatment groups. Next, we tested treatment effects controlling for baseline violence, site, design effects and adherence. Then we conducted multivariable analysis of clinical and non-clinical predictors of violence. Finally, we performed subgroup analysis in two theoretically and empirically significant risk strata - patients with and without childhood antisocial conduct history.

The treatment effects on violence at 6 months for the retained sample were examined using mixed-model logistic regression analysis, ${ }^{29-31}$ with a dummy variable for each second-generation antipsychotic compared with perphenazine as the omitted reference category, controlling for baseline violence and adherence to medication. Trends in the rate of violence across medication groups were tested using repeated-measures logistic regression analysis, comparing violence at baseline and 6 months, with controls for design effects, covariance of within-participant observations and site effects. The statistical models also included proxy variables for whether the participant was recruited before or after the introduction of ziprasidone, and whether the participant had tardive dyskinesia at baseline. Site was entered as a random effect for all multivariable models.

The violence multivariable prediction analyses followed a similar approach and were conducted in three stages. First, bivariate associations were estimated between violence and baseline predictors across the five domains. Next, separate multivariable models were estimated for each domain. Variables representing treatment and design effects were carried forward in all models irrespective of level of significance, although coefficients for design effects are not displayed in the tables. Other covariates were retained at $P<0.15$ with stepwise selection. All covariates selected in the domain models were then entered into a final model, also with selection at $P<0.15$.

\section{Results}

\section{Sample characteristics}

In the intention-to-treat sample the median age of participants was 42 years. This sample was $74 \%$ male, $60 \%$ White and $35 \%$ African American. Clinically the sample was moderately symptomatic. The mean PANSS negative symptom score was 20 (possible range 7-49) and the mean positive symptom score was 18 (possible range 7-49). The sample's mean score on the Calgary Depression Scale was 4.6 (possible range 0-27). Thirty-six per cent had a substance misuse or dependence disorder; an additional $25 \%$ used alcohol or illicit drugs without significant impairment. Twenty-seven per cent had a recent hospitalisation or episode of crisis care. The mean time since first treatment with an antipsychotic medication was more than 16 years.

The characteristics of the retained sample were similar to the intention-to-treat sample (further information is presented in the online Table DS1). However, participants retained at 6 months were less likely to have been violent at baseline than the full intention-to-treat sample (16\% v. 19\%). This difference occurred because participants with a baseline history of violence were more likely to discontinue their phase 1 medication and leave the study than those with no baseline history of violence.

\section{Overall prevalence of violence and change in violence rate from baseline to 6 months}

Table 1 displays rates of violence for the medication groups at baseline and 6 months, comparing the intention-to-treat sample and the retained sample. The estimated rate of violence declined from $19 \%$ to $14 \%$ in the intention-to-treat sample, whereas the observed rate declined from $16 \%$ to $9 \%$ in the retained sample. The proportional magnitude of decline in violence was substantially greater in the retained sample than in the intention-to-treat sample ( $43 \%$ v. $27 \%$ decline). We used repeated-measures logistic regression analysis to examine the significance of the decline in violence risk across the whole sample from baseline to 6 months. Among participants retained in the study, the adjusted odds of violence were approximately halved $(\mathrm{OR}=0.52$, 95\% CI 0.38 $0.71 ; P<0.001)$; among those who discontinued medication or withdrew from the study, the finding was less dramatic ( $\mathrm{OR}=0.77,95 \%$ CI $0.60-0.99 ; P<0.05)$.

\section{Treatment effects}

The treatment groups did not differ significantly from each other on violence outcomes in the intention-to-treat sample. In the retained sample, patients assigned to perphenazine showed a greater reduction in violence risk - from $19 \%$ at baseline to $7 \%$ at follow-up - when compared with patients assigned to quetiapine, whose risk of violence declined from $15 \%$ to $14 \%$ over the same period. Perphenazine did not differ from olanzapine, risperidone or ziprasidone. Table 1 presents a test of these treatment effects using logistic regression. Baseline violence was also a strong predictor of violence at 6 months $(\mathrm{OR}=6.28,95 \%$ CI $3.63-10.86 ; P<0.001)$, and was included as a control in the 


\begin{tabular}{|c|c|c|c|c|c|c|c|c|c|}
\hline & \multirow{2}{*}{\multicolumn{4}{|c|}{$\begin{array}{l}\text { Intention-to-treat sample at } 6 \text { months }^{\text {a }} \\
\qquad(n=1445) \\
\text { Any violence, } \%\end{array}$}} & \multicolumn{4}{|c|}{$\begin{array}{l}\text { Retained sample at } 6 \text { months } \\
\qquad(n=653)\end{array}$} & \multirow[t]{2}{*}{$\begin{array}{l}\text { Logistic regression model }^{\mathrm{b}} \\
\text { Retained sample at } 6 \text { months } \\
\qquad(n=653)\end{array}$} \\
\hline & & & & & & Any viol & ence, \% & & \\
\hline & $n$ & Baseline & $\begin{array}{l}\text { 6-month } \\
\text { follow-up }\end{array}$ & Change & $n$ & Baseline & $\begin{array}{l}\text { 6-month } \\
\text { folow-up }\end{array}$ & Change & OR $(95 \% \mathrm{Cl})$ \\
\hline \multicolumn{10}{|c|}{ Phase 1 treatment group } \\
\hline Perphenazine & 259 & 22.0 & 14.3 & -35.1 & 114 & 19.3 & 7.0 & -63.6 & {$[1.0]$} \\
\hline Risperidone & 337 & 17.8 & 13.4 & -25.0 & 153 & 15.1 & 11.8 & -22.3 & $1.29(0.96-1.72)$ \\
\hline Olanzapine & 331 & 19.6 & 13.0 & -33.9 & 185 & 16.8 & 7.6 & -54.8 & $1.20(0.49-2.95)$ \\
\hline Ziprasidone & 184 & 20.1 & 15.2 & -24.3 & 70 & 15.7 & 4.3 & -72.7 & $0.96(0.73-1.27)$ \\
\hline Quetiapine & 334 & 17.1 & 14.7 & -14.1 & 131 & 14.5 & 13.7 & -5.2 & $1.65(1.07-2.57)^{\star}$ \\
\hline Total & 1445 & 19.1 & 14.0 & -26.8 & 653 & 16.3 & 9.3 & -42.6 & \\
\hline
\end{tabular}

model along with controls for site, design effects and adherence to assigned medication.

\section{Predictors of violence at 6 months}

Table 2 presents bivariate and adjusted odds ratios for baseline covariates predicting violence at 6 months for the retained sample. In multivariable analysis across domains, a final model identified several significant prospective predictors of violence: economic deprivation, living with family or unrelated others $v$. living alone, history of childhood conduct problems, substance use or misuse/ dependence and history of violent victimisation. Negative psychotic symptoms were associated with significantly lower risk of violence.

\section{Medication adherence and violence in persons with and without history of childhood antisocial conduct}

Overall, medication adherence was not significantly associated with 6-month violence. However, when the sample was stratified into those with a history of childhood antisocial conduct problems $(n=488)$ and those without a history of conduct problems $(n=956)$, adherence to antipsychotic medications was found to significantly reduce violence only in the group without a history of conduct problems $(\mathrm{OR}=0.47,95 \%$ CI $0.27-0.81$; $P<0.01)$. In the conduct problems group, the effect of medication adherence on violence reduction was in the same direction but not statistically significant ( $\mathrm{OR}=0.59,95 \%$ CI $0.32-1.09)$.

\section{Discussion}

The key finding of our study was that violence was reduced across all treatment groups, declining from a prevalence of $16 \%$ to $9 \%$ in the retained sample and from $19 \%$ to $14 \%$ in the intentionto-treat sample. No difference by medication was found, with the exception that perphenazine showed greater reduction in violence than quetiapine in the retained sample only. Medication adherence across all treatment groups was significantly associated with reduced violence, except in patients with a history of childhood antisocial conduct. Significant prospective predictors of violence included childhood conduct problems, substance misuse, victimisation history, economic deprivation and social living situation; living with others, rather than alone, increased violence risk. Negative psychotic symptoms predicted lower violence. Placing these findings in context, it is important to emphasise that the large majority of people with schizophrenia do not commit violent acts. ${ }^{32,33}$ Nevertheless, a substantial body of research suggests that violence risk is significantly elevated for individuals with psychotic disorders and symptoms, especially in combination with other risk factors such as substance misuse and victimisation history. ${ }^{13,18,32,34-38}$ Evidence for the relationship between psychotic symptoms and violence is controversial and somewhat mixed. For example, findings from the MacArthur Violence Risk Assessment study found no relationship between delusions and violence. ${ }^{39}$ However, psychiatrists have widely assumed that effective treatment with antipsychotic medications has a key role in reducing the risk of violence in patients with schizophrenia, and that the new antipsychotic drugs would be even more effective than the older medications in managing violence risk.

In the CATIE study we examined the relative risk of violent behaviour as an outcome of treatment with one of four secondgeneration antipsychotics compared with perphenazine, a representative first-generation drug. Contrary to the expectations of many clinicians and some previous research, these findings show no advantage for the second-generation antipsychotics in reducing violent behaviour over a 6-month follow-up period. Indeed, quetiapine performed worse than perphenazine. As a general trend, and confirming prior research, ${ }^{14}$ the rate of violent behaviour declined significantly across all treatment groups, especially in the retained sample, with a reduction of $42 \%$ from baseline to follow-up. Estimated rates of violence also declined in the intention-to-treat sample, although the decline was less pronounced. Adherence to medications reduced violence at 6 months, controlling for baseline violence and medication group, but only in patients without a history of childhood conduct problems.

These findings provoke new questions about prior research on second-generation antipsychotics and violence, and about the role of medication in managing violence risk in some patients with schizophrenia who may be violent for reasons unrelated to psychosis. On the surface there appear to be inconsistencies between the current results and previous research. However, in several ways the studies are not fully comparable. First, some of the previous studies that found an advantage for second- over first-generation antipsychotics in reducing violence included clozapine among the former and haloperidol among the latter. Clozapine has the most convincing body of evidence for an anti-aggressive effect, whereas high doses of haloperidol have been associated with some poorer outcomes, including aggression. ${ }^{40}$ Neither of these drugs was included in CATIE phase 1. Another difference is that naturalistic 


\begin{tabular}{|c|c|c|c|}
\hline & \multicolumn{3}{|c|}{ Any violence } \\
\hline & $\begin{array}{l}\text { Bivariate associations } \\
\quad \text { OR }(95 \% \mathrm{Cl})\end{array}$ & $\begin{array}{l}\text { Domain models } \\
\text { OR }(95 \% \mathrm{Cl})\end{array}$ & $\begin{array}{l}\text { Violence prediction final model } \\
\text { OR }(95 \% \mathrm{Cl})\end{array}$ \\
\hline \multicolumn{4}{|c|}{$\begin{array}{l}\text { Model 1: Demographic characteristics, social stratification } \\
\text { and housing }\end{array}$} \\
\hline Age & $0.96(0.93-0.98)^{* * *}$ & $0.96(0.94-0.99)^{* *}$ & $0.97(0.95-1.00)$ \\
\hline Male & $1.05(0.58-1.91)$ & & \\
\hline White & $1.31(0.75-2.28)$ & & \\
\hline Cohabitation & $1.16(0.61-2.23)$ & & \\
\hline High income & $0.47(0.27-0.81)^{* *}$ & $0.47(0.26-0.85)^{*}$ & $0.54(0.28-1.03)$ \\
\hline Education (beyond high school) & $0.87(0.51-1.48)$ & & \\
\hline Substantial vocational activity & $0.94(0.33-2.63)$ & & \\
\hline \multicolumn{4}{|l|}{ Housing during past 30 days } \\
\hline Extremely restrictive & $0.76(0.30-1.94)$ & & \\
\hline Homeless & $1.02(0.14-7.64)$ & & \\
\hline \multirow[t]{2}{*}{ Economic scarcity } & $2.83(0.91-8.73)$ & $3.31(1.01-10.82)^{\star}$ & $4.84(1.29-18.09)^{\star}$ \\
\hline & \multicolumn{3}{|c|}{$n=646$} \\
\hline \multirow{2}{*}{\multicolumn{4}{|c|}{$\begin{array}{l}\text { Model 2: Household composition and social contact } \\
\text { Currently live with }\end{array}$}} \\
\hline & & & \\
\hline \multicolumn{4}{|l|}{ Alone (reference) } \\
\hline Family/other relatives & $2.99(1.41-6.37)^{\star *}$ & $2.96(1.37-6.38)^{\star *}$ & $2.73(1.14-6.56)^{*}$ \\
\hline Other people not related & $3.14(1.37-7.20)^{\star \star}$ & $3.23(1.40-7.42)^{* *}$ & $3.29(1.28-8.47)^{\star}$ \\
\hline Frequent contact with family and friends & $1.17(0.52-2.59)$ & & \\
\hline Feel 'listened to' most of the time by family & $0.78(0.46-1.31)$ & & \\
\hline \multicolumn{4}{|c|}{$n=650$} \\
\hline \multicolumn{4}{|l|}{ Model 3: Childhood risk factors } \\
\hline Childhood physicial abuse & $1.74(0.98-3.10)$ & & \\
\hline Childhood sexual abuse & $1.92(1.07-3.48)^{*}$ & & \\
\hline Childhood conduct problems (above median 2+) & \multicolumn{3}{|c|}{$n=653$} \\
\hline \multicolumn{4}{|l|}{$\begin{array}{l}\text { Model 4: Baseline clinical characteristics, impairment } \\
\text { and functioning }\end{array}$} \\
\hline Clinical Global Impression & $0.95(0.54-1.68)$ & & \\
\hline PANSS Negative & $0.96(0.92-0.99)^{*}$ & $0.96(0.91-1.00)$ & $0.94(0.90-0.99)^{*}$ \\
\hline PANSS Positive & $1.03(0.99-1.08)$ & & \\
\hline Calgary & $1.07(1.01-1.13)^{*}$ & $1.07(1.01-1.14)^{*}$ & $1.07(0.99-1.14)$ \\
\hline Insight (median) & $0.83(0.49-1.40)$ & & \\
\hline Years in treatment & $0.99(0.96-1.01)$ & & \\
\hline \multicolumn{4}{|l|}{ Substance use } \\
\hline \multicolumn{4}{|l|}{ Abstinent (reference) } \\
\hline Use & $3.73(1.64-4.55)^{\star * *}$ & $3.38(1.46-7.86)^{* *}$ & $3.31(1.33-8.23)^{\star}$ \\
\hline Misuse/dependence & $4.91(2.29-10.53)^{\star \star * *}$ & $4.46(2.04-9.75)^{\star \star * *}$ & $3.85(1.65-9.02)^{\star *}$ \\
\hline \multicolumn{4}{|l|}{ Victimisation prior to study enrolment } \\
\hline Violently victimised (12 months) & $3.97(1.24-12.73)^{\star}$ & $3.81(1.09-13.38)^{*}$ & $4.51(1.06-19.20)^{*}$ \\
\hline Non-violently victimised (12 months) & $0.70(0.22-2.23)$ & & \\
\hline \multicolumn{4}{|l|}{ Heinrich-Carpenter Quality of Life } \\
\hline Common objects and activities subscale & $0.84(0.67-1.05)$ & & \\
\hline Instrumental role subscale & $0.82(0.69-0.97)^{*}$ & $0.79(0.65-0.96)^{*}$ & $0.83(0.68-1.02)$ \\
\hline Intrapsychic foundations subscale & $0.92(0.74-1.15)$ & & \\
\hline Interpersonal relations subscale & $1.12(0.93-1.35)$ & $1.20(0.95-1.52)$ & \\
\hline \multirow[t]{2}{*}{ Satisfaction with life } & $0.79(0.44-1.43)$ & & \\
\hline & \multicolumn{3}{|c|}{$n=645$} \\
\hline \multicolumn{4}{|l|}{ Model 5: Institutional contact prior to study enrolment } \\
\hline Total prior hospitalisation (lifetime 4+) & $1.28(0.76-2.14)$ & & \\
\hline Total prior hospitalisations (12 months $1+$ ) & $1.15(0.67-1.97)$ & & \\
\hline \multirow[t]{2}{*}{ Arrested or picked up for crime (6 months) } & $1.71(0.71-4.13)$ & & \\
\hline & & & $n=642$ \\
\hline
\end{tabular}

studies have tended to include more stable patients and have followed them over a longer period. ${ }^{2}$ Finally, there are measurement differences: some previous studies have used continuous measures to describe violence, ${ }^{41,42}$ whereas we used a dichotomous indicator of the presence or absence of any violence. All of these methodological and design differences may help explain why there are discrepant findings, and may temper the impulse to discount the older research.
We also identified significant prospective predictors of violence: economic deprivation, living with family or unrelated others $v$. living alone, childhood conduct problems, substance use or misuse/dependence, and violent victimisation. Negative psychotic symptoms were associated with lower risk of violence. These results are generally consistent with findings in the baseline CATIE data. ${ }^{13}$ However, some significant correlates that were identified in the baseline analysis - positive psychotic symptoms, 
for example - were not found to be significant as prospective predictors. Such differences may be explained by the lack of temporal contiguity between the assessment of risk and the follow-up assessment; for example, patients with psychotic symptoms at baseline might not have had psychotic symptoms after treatment during the follow-up period, which was the period of observation for violence. Differences may also be explained by attrition associated with baseline violence, and the reduction in statistical power resulting from patients who discontinued medication or withdrew from the study by 6 months.

In considering possible mechanisms of anti-aggressive action of these medications, it is important to bear in mind that aggressive behaviour may have a number of different causes, and that people with schizophrenia often have heterogeneous symptoms and co-occurring disorders that may increase violence risk. Persistently violent patients with schizophrenia with co-occurring antisocial personality or psychopathic features ${ }^{43}$ may not become less violent with antipsychotic medication alone. In our study the strong predictive effect of baseline violence on future violence indicates its long-term persistence in some of these patients irrespective of treatment. ${ }^{12}$ The fact that adherence to antipsychotic medication did not significantly reduce violent behaviour in patients with childhood antisocial history is consistent with the view that much of the violence in these patients was not caused by their psychosis, and thus was not likely to be reduced by antipsychotic medications. Differences among pharmacological drug effects may be obscured under such conditions.

Understanding the role of antipsychotic medication in reducing violence risk among people with schizophrenia in the community has long challenged researchers and clinicians alike. Findings from this study help to clarify both the importance and the limitations of pharmacotherapy for violence risk management. However, this study itself has significant limitations. First, the absence of a placebo condition in the design prevents us from examining the effectiveness of antipsychotics compared with no medication, although examining non-adherence provides an uncontrolled finding of an effect for not taking medication as prescribed. Second, a large proportion of the originally enrolled cohort discontinued their prescribed antipsychotic medication, which limits the evidence regarding the potential efficacy of these drugs. Third, the CATIE study did not selectively recruit patients with a history of serious violence, but rather, violence was one of many outcomes evaluated over the course of the study. For this reason, and because the population base rate of serious violence is very low, we were unable to examine effects of medication for different levels of severity of violence. Fourth, and finally, we were only able to focus on the first 6 months of the 18month CATIE trial, as too few patients remained on their assigned phase 1 medication to allow for a valid longer-term analysis of violence.

In summary, contrary to high expectations and some previous research, this study did not show an advantage for secondgeneration antipsychotics in violence risk reduction when compared with perphenazine, a representative first-generation antipsychotic, among patients taking their prescribed medication for 6 months. Our violence prediction model suggests that a number of social and environmental factors might cause violence independently of psychopathology. Therefore, more intensive psychosocial or family-based supportive interventions may be needed to substantially reduce violent behaviour in patients with other risk factors. Indeed, for patients with many developmental, social and environmental risk factors, even optimal pharmacotherapy might not reduce violent behaviour; pharmacotherapy alone cannot be expected to mitigate essentially non-clinical causes of violence. ${ }^{12}$ Still, psychosis can play a central part in violence in some patients with schizophrenia, ${ }^{13}$ and may become intertwined with additional causes of violence in other patients. ${ }^{12}$ Effective antipsychotic medications are needed, along with psychosocial and supportive interventions to improve treatment adherence and social functioning, in order to effectively reduce violence risk in people with schizophrenia.

Jeffrey W. Swanson, PhD, Marvin S. Swartz, MD, Department of Psychiatry and Behavioral Sciences, Duke University Medical Center, Durham, North Carolina; Richard A. Van Dorn, PhD, College of Social Work, Justice, and Public Affairs, Miami, Florida International University; Jan Volavka, MD, PhD, New York University, New York; John Monahan, PhD, University of Virginia School of Law, Charlottesville, Virginia; T. Scott Stroup, MD, MPH, Department of Psychiatry and Behavioral Sciences, University of North Carolina at Chapel Hill, North Carolina; Joseph P. McEvoy, MD, PhD, H. Ryan Wagner, PhD, Eric B. Elbogen, PhD, Department of Psychiatry and Behavioral Sciences, Duke University Medical Center, Durham, North Carolina; Jeffrey A. Lieberman, MD, Department of Psychiatry, College of Physicians and Surgeons, Columbia University, New York State Psychiatric Institute, New York, USA

Correspondence: Professor Jeffrey Swanson, Department of Psychiatry and Behavioral Sciences, Duke University School of Medicine, DUMC Box 3071, Brightleaf Square Suite 23-A, 905 West Main Street, Durham, NC 27710, USA Email jeffrey.swanson@duke.edu

First received 4 Jul 2007, final revision 15 Feb 2008, accepted 26 Feb 2008

\section{Acknowledgements}

This article was based on results from the Clinical Antipsychotic Trials of Intervention Effectiveness (CATIE) project, supported with US Federal funds from the National Institute of Mental Health (NIMH) under contract NO1 MH90001. The aim of this project was to examine the comparative effectiveness of antipsychotic drugs in conditions for which their use is clinically indicated, including schizophrenia and Alzheimer's disease. The project was carried out by principal investigators from the University of North Carolina, Duke University, the University of Southern California, the University of Rochester and Yale University in association with Quintiles, Inc.; the program staff of the Division of Interventions and Services Research of the NIMH; and investigators from 56 sites in the USA (CATIE Study Investigators Group). AstraZeneca Pharmaceuticals LP, Bristol-Myers Squibb Company, Forest Pharmaceuticals, Inc., Janssen Pharmaceutica Products, L.P., Eli Lilly and Company, Otsuka Pharmaceutical Co., Ltd., Pfizer, Inc., and Zenith Goldline Pharmaceuticals, Inc., provided medications for the studies. This work was also supported by the Foundation of Hope of Raleigh, North Carolina. The CATIE Study Investigators Group includes Lawrence Adler, MD, Clinical Insights; Mohammed Bari, MD, Synergy Clinical Research; Irving Belz, MD, Tri-County/ MHMR; Raymond Bland, MD, SIU School of Medicine; Thomas Blocher, MD, MHMRA of Harris County; Brent Bolyard, MD, Cox North Hospital; Alan Buffenstein, MD, The Queen's Medical Center; John Burruss, MD, Baylor College of Medicine; Matthew Byerly, MD, University of Texas Southwestern Medical Center at Dallas; Jose Canive, MD, Albuquerque VA Medical Center; Stanley Caroff, MD, Behavioral Health Service; Charles Casat, MD, Behavioral Health Center; Eugenio Chavez-Rice, MD, El Paso Community MHMR Center; John Csernansky, MD, Washington University School of Medicine; Pedro Delgado, MD, University Hospitals of Cleveland; Richard Douyon, MD, VA Medical Center; Cyril D'Souza, MD, Connecticut Mental Health Center; Ira Glick, MD, Stanford University School of Medicine; Donald Goff, MD, Massachusetts General Hospital; Silvia Gratz, MD, Eastern Pennsylvania Psychiatric Institute; George T. Grossberg, MD, St Louis University School of Medicine - Wohl Institute; Mahlon Hale, MD, New Britain General Hospital; Mark Hamner, MD, Medical University of South Carolina and Veterans Affairs Medical Center; Richard Jaffe, MD, Belmont Center for Comprehensive Treatment; Dilip Jeste, MD, University of California-San Diego, VA Medical Center; Anita Kablinger, MD, Louisiana State University Health Sciences Center; Ahsan Khan, MD, Psychiatric Research Institute; Steven Lamberti, MD, University of Rochester Medical Center; Michael T, Levy, MD, PC, Staten Island University Hospital; Jeffrey Lieberman, MD, University of North Carolina at Chapel Hill; University Hospital; Jeffrey Lieberman, MD, University of North Carolina at Chapel Hill;
Gerald Maguire, MD, University of California Irvine; Theo Manschreck, MD, Corrigan Mental Health Center; Joseph McEvoy, MD, Duke University Medical Center; Mark McGee, MD, Appalachian Psychiatric Healthcare System; Herbert Meltzer, MD, Vanderbilt University Medical Center; Alexander Miller, MD, University of Texas Health Science Center at San Antonio; Del D. Miller, MD, University of Iowa; Henry Nasrallah, MD, University of Cincinnati Medical Center; Charles Nemeroff, MD, PhD, Emory University School of Medicine; Stephen Olson, MD, University of Minnesota Medical School; Gregory F. Oxenkrug, MD, St. Elizabeth's Medical Center; Jayendra Patel, MD, University of Mass Health Care; Frederick Reimherr, MD, University of Utah Medical Center; Silvana Riggio, MD, Mount Sinai Medical Center-Bronx VA Medical Center; Samuel Risch, MD, University of California-San Francisco; Bruce Saltz, MD, Henderson Mental Health Center; Thomas Simpatico, MD, Northwestern University; George Simpson, MD, University of Southern California Medical Center; Michael Smith, MD, Harbor - UCLA Medical Center; Roger Sommi, PharmD, University of Missouri; Richard M. Steinbook, MD, University of Miami School of Medicine; Michael Stevens, MD, Valley Mental Health; Andre Tapp, MD, VA Puget Sound Health Care System; Rafael Torres, MD, University of Mississippi; Peter Weiden, MD, SUNY Downstate Medical Center; James Wolberg, MD, Mount Sinai Medical Center. The study was also supported by the National Institute of Mental Health through an Independent Research Scientist Career Award to J.S.

\section{References}

1 Walsh E, Buchanan A, Fahy T. Violence and schizophrenia: examining the evidence. Br J Psychiatry 2002; 180: 490-5. 
2 Swanson JW, Swartz MS, Elbogen EB. Effectiveness of atypical antipsychotic medications in reducing violent behavior among persons with schizophrenia in community-based treatment. Schizophr Bull 2004; 30: 3-20.

3 Buckley PF. The role of typical and atypical antipsychotic medications in the management of agitation and aggression. J Clin Psychiatry 1999; 60: 52-60.

4 Buckley PF, Bartell J, Donenwirth K, Lee S, Torigoe F, Schulz SC. Violence and schizophrenia: clozapine as a specific antiaggressive agent. Bull Am Acad Psychiatry Law 1995; 23: 607-11.

5 Citrome L, Krakowski M, Greenberg WM, Andrade E, Volavka J. Antiaggressive effect of quetiapine in a patient with schizoaffective disorder J Clin Psychiatry 2001; 62: 901.

6 Taylor PJ, Butwell M, Gray C, Daly R, Delal B, Ferraro D, Gibb R, Heads T, Huckstep B, Larkin E, Leese M, Shetty G, Winton M, Tidmarsh D, Williams D. Schizophrenia, violence, clozapine and risperidone: a review. Br J Psychiatry 1996; 169: 21-30.

7 Volavka J. The effects of clozapine on aggression and substance abuse in schizophrenic patients. J Clin Psychiatry 1999; 60: 43-6.

8 Volavka J, Czobor P, Sheitman B, Lindenmayer JP, Citrome L, McEvoy JP, Cooper TB, Chakos M, Lieberman JA. Clozapine, olanzapine, risperidone, and haloperidol in the treatment of patients with chronic schizophrenia and schizoaffective disorder. Am J Psychiatry 2002; 159: 255-62.

9 Lieberman JA, Stroup TS, McEvoy JP, Swartz MS, Rosenheck RA, Perkins DO Keefe RS, Davis SM, Davis CE, Lebowitz BD, Severe J, Hsiao JK. Effectiveness of antipsychotic drugs in patients with chronic schizophrenia. N Engl J Med 2005; 353: 1209-23.

10 Jones PB, Barnes TRE, Davies L, Dunn G, Lloyd H, Hayhurst KP, Murray RM, Markwick A, Lewis SW. Randomized controlled trial of the effect on quality of life of second- vs first-generation antipsychotic drugs in schizophrenia: Cost Utility of the Latest Antipsychotic Drugs in Schizophrenia Study (CUtLASS 1) Arch Gen Psychiatry 2006; 63: 1079-87.

11 Tiihonen J, Walhbeck K, Lonnqvist J, Klaukka T, Ioannidis JP, Volavka J, Haukka J. Effectiveness of antipsychotic treatments in a nationwide cohort of patients in community care after first hospitalisation due to schizophrenia and schizoaffective disorder: observational follow-up study. BMJ 2006; 333 224-7.

12 Swanson JW, Van Dorn RA, Swartz MS, Smith A, Elbogen EB, Monahan J. Alternative pathways to violence in persons with schizophrenia: the role of childhood antisocial behavior problems. Law Hum Behav, in press.

13 Swanson JW, Swartz MS, Van Dorn RA, Elbogen EB, Wagner HR, Rosenheck RA, Stroup TS, McEvoy JP, Lieberman JA. A national study of violent behavior in persons with schizophrenia. Arch Gen Psychiatry 2006; 63: 490-9.

14 Steadman HJ, Mulvey EP, Monahan J, Robbins PC, Appelbaum PS, Grisso T, Roth $\mathrm{LH}$, Silver E. Violence by people discharged from acute psychiatric inpatient facilities and by others in the same neighborhoods. Arch Gen Psychiatry 1998; 55: 393-401.

15 Swanson JW, Swartz MS, Elbogen EB, Van Dorn RA. Reducing violence risk in persons with schizophrenia: olanzapine vs. risperidone. J Clin Psychiatry 2004; 65: 1666-73.

16 Stroup TS, McEvoy JP, Swartz MS, Byerly MJ, Glick ID, Canive JM, McGee MF, Simpson GM, Stevens MC, Lieberman JA. The National Institute of Mental Health Clinical Antipsychotic Trials of Intervention Effectiveness (CATIE) project: schizophrenia trial design and protocol development. Schizophr Bull 2003; 29: 15-31.

17 Monahan J, Steadman $\mathrm{H}$ (eds). Violence and Mental Disorder: Developments in Risk Assessment. University of Chicago Press, 1994.

18 Link BG, Stueve A, Phelan J. Psychotic symptoms and violent behaviors: probing the components of 'threat/control override' symptoms. Soc Psychiatry Psychiatr Epidemiol 1998; 33: s55-60.

19 Swanson J, Estroff S, Swartz M, Borum R, Lachicotte W, Zimmer C, Wagner R. Violence and severe mental disorder in clinical and community populations: the effects of psychotic symptoms, comorbidity, and lack of treatment. Psychiatry 1997; 60: 1-22.

20 Farrington DP, Loeber R. Some benefits of dichotomization in psychiatric and criminological research. Crim Behav Ment Health 2000; 10: 100-22.

21 George L, Blazer D, Hughes D, Fowler N. Social support and the outcomes of major depression. Br J Psychiatry 1989; 186: 651-6.
22 First MB, Spitzer RL, Gibbon M, Williams JBW. Structured Clinical Interview for Axes I and II DSM-IV Disorders - Patient Edition (SCID-I/P). Biometrics Research Department, New York State Psychiatric Institute, 1996.

23 Guy W. Early Clinical Drug Evaluation (ECDEU) Assessment Manual. National Institute of Mental Health, 1976.

24 Kay SR, Fiszbein A, Opler LA. The positive and negative syndrome scale (PANSS) for schizophrenia. Schizophr Bull 1987; 13: 261-76.

25 Addington D, Addington J, Schissel B. A depression rating scale for schizophrenics. Schizophr Res 1990; 3: 247-51.

26 McEvoy JP, Aland JJ, Wilson WH, Guy W, Hawkins L. Measuring chronic schizophrenic patients attitudes toward their illness and treatment. Hosp Community Psychiatry 1981; 32: 856-8.

27 Swartz MS, Wagner HR, Swanson JW, Stroup TS, McEvoy JP, Canive JM, Miller $D D$, Reimherr $F$, McGee $M$, Khan A, Van Dorn R, Rosenheck RA, Lieberman JA. Substance use in persons with schizophrenia: baseline prevalence and correlates from the NIMH CATIE study. J Nerv Ment Dis 2006; 194: 164-72.

28 Heinrichs DW, Hanlon ET, Carpenter WT. The quality of life scale: an instrument for rating the schizophrenic deficit syndrome. Schizophr Bull 1984; 10: 388-98.

29 Fleiss JL, Williams JB, Dubro AF. The logistic regression analysis of psychiatric data. J Psychiatr Res 1986; 20: 145-209.

30 Hosmer D, Lemeshow S. Applied Logistic Regression (2nd edn). Wiley, 2000.

31 Snijders TAB, Bosker RJ. Multilevel Analysis: An Introduction to Basic and Advanced Multilevel Modeling. Sage, 1999.

32 Swanson JW. Mental disorder, substance abuse, and community violence: an epidemiological approach. In Violence and Mental Disorder: Developments in Risk Assessment (eds J Monahan, H Steadman): 101-36. University of Chicago Press, 1994.

33 Wallace $C$, Mullen PE, Burgess P. Criminal offending in schizophrenia over a 25-year period marked by deinstitutionalization and increasing prevalence of comorbid substance use disorders. Am J Psychiatry 2004; 161: 716-27.

34 Hiday VA, Swanson JW, Swartz MS, Borum R, Wagner HR. Victimization: a link between mental illness and violence? Int J Law Psychiatry 2001; 24: 559-72.

35 Link BG, Stueve A. Psychotic symptoms and the violent/illegal behavior of mental patients compared to community controls. In Violence and Mental Disorder: Developments in Risk Assessment (eds J Monahan, H Steadman): 137-160. University of Chicago Press, 1994.

36 Mullen PE. Schizophrenia and violence: from correlations to preventive strategies. Advan Psychiatr Treat 2006; 12: 239-48.

37 Swanson JW, Borum R, Swartz MS, Monahan J. Psychotic symptoms and disorders and the risk of violent behavior in the community. Crim Behav Ment Health 1996; 6: 317-38.

38 Swanson JW, Swartz MS, Essock SM, Osher FC, Wagner HR, Goodman LA, Rosenberg SD, Meador KG. The social-environmental context of violent behavior in persons treated for severe mental illness. Am J Publ Health 2002; 92: 1523-31.

39 Appelbaum PS, Robbins PC, Monahan J. Violence and delusions: data from the MacArthur Violence Risk Assessment Study. Am J Psychiatry 2000; 157: 566-72.

40 Herrera JN, Sramek JJ, Costa JF, Roy S, Heh CW, Nguyen BN. High potency neuroleptics and violence in schizophrenics. J Nerv Ment Dis 1988; 176: $558-61$.

41 Krakowski Ml, Czobor P, Citrome L, Bark N, Cooper TB. Atypical antipsychotic agents in the treatment of violent patients with schizophrenia and schizoaffective disorder. Arch Gen Psychiatry 2006; 63: 622-9.

42 Volavka J, Czobor P, Nolan K, Sheitman B, Lindenmayer JP, Citrome L, McEvoy JP, Cooper TB, Lieberman JA. Overt aggression and psychotic symptoms in patients with schizophrenia treated with clozapine, olanzapine, risperidone, or haloperidol. J Clin Psychopharmacol 2004; 24: 225-8.

43 Nolan KA, Volavka J, Mohr P, Czobor P. Psychopathy and violent behavior among patients with schizophrenia or schizoaffective disorder. Psychiatr Serv 1999; 50: 787-92. 